\title{
Making the Grade: Measuring Completers' Impact on K-12 Learning
}

\author{
Diana M. Yesbeck \\ Randolph-Macon College \\ Savanna M. Love \\ Randolph-Macon College
}

Teacher preparation programs measure success in multiple ways. This mixed-methods study measures completers' impact on K-12 classroom learning to satisfy national accreditation and for our continuous improvement model. Our teacher preparation program uses an ongoing process to improve program products, services, and processes through constant review, measurement, and action. To determine completers' effectiveness and impact on K-12 learning, we developed a five-prong approach to measure practices which are accurate and effective. We developed, validated, and implemented four proprietary instruments to determine the effectiveness of its completers in applying expected professional knowledge, skills, and dispositions to positively impact student learning.

Keywords: completer, accreditation, CAEP, evaluation

\section{INTRODUCTION}

Producing quality teachers who can positively impact student achievement is the goal of any teacher preparation program. More than ever before, we are aware of the critical role teachers and classroom instruction play in the student performance (Shulman, 1986; National Academy of Education, 2005). Therefore, the importance of evaluating teacher preparation programs has become increasingly apparent (National Research Council, 2010).

Our teacher preparation program relies on our quality assurance program to systematically monitor and evaluate various aspects of the program to ensure that standards of quality are being met. The Educator Preparation Program's (EPP) Domains of Leaning and Student Learning Objectives successfully prepare candidates and completers in areas of learner development and learning differences; instructional planning and content knowledge; assessment; professional dispositions; synthesis, and reflective practices. Before clinical experiences commence, teacher candidates complete 60-100 hours of fieldwork in local classrooms; successfully pass mandated standardized assessments; complete applications to the teacher preparation program, and complete program assessments, designed to measure their growth over time, related to diversity, teacher dispositional factors, and professional knowledge and skills. We have an outstanding rate of completer employment rate upon graduation. Over the past four years, 100\% of teacher candidates secured teaching positions for the following academic year in their fields.

The EPP offers a state approved and nationally accredited program, accredited by the Council for the Accreditation of Educator Preparation (CAEP) which certifies that the professional education program 
has provided evidence that the program adheres to CAEP's quality principles. The EPP offers a minor in education which is a sequential program designed to enable qualified students to teach elementary, secondary, special education, or music. The required education courses must be combined appropriately with specified general education courses and with the requisite courses in the student's major program. All requirements and coursework fulfill current state guidelines for teacher licensure. The structured programs enable students to meet the requirements prescribed by the State Board of Education for the Collegiate Professional License in fourteen endorsements.

Importantly, preparing teacher candidates for the classroom doesn't stop at graduation. It is our goal to maintain meaningful relationships with completers, continuing the service as mentors and teachers to help guide their success once they leave our program. As we prepared our teacher candidates through the program, we were directly impacting their growth; now the completers will directly impact K-12 student growth, which means that we, as their professors, continue to directly and indirectly impact growth and success. The purpose of this study is to measure the impact of growth and success for both the completers and their students as they transition from the college classroom to their K-12 classroom. A secondary purpose is to explore the effectiveness of our five-prong approach in measuring completer success.

Accreditation standards require teacher preparation programs to effectively measure completer impact and success using a uniform and strategic plan of action. Prior to implementing our five-prong approach, we maintained positive relationships with our alumni (completers) and regularly visited first-year teachers in their classrooms. Therefore, we built on already-established relationships to develop additional assessments to meet accreditation standards of measuring the effectiveness of our completers by developing several instruments to gather quantitative and qualitative data as evidence of their effectiveness. In our state, the department of education does not share K-12 state standardized test scores; as such, each EPP (educator preparation program) in the state built their own strategy. Specifically, we designed assessments to measure completer effectiveness and developed a continuous improvement plan to collect and analyze data for program improvement. In order to evaluate our goals of producing highly qualified teachers, we found it important to collect multiple forms of data from a variety of sources. This allowed us to obtain important perspectives that could lead to actionable evidence related to completer impact on K-12 learning.

\section{CONNECTION TO THE LITERATURE}

The current research is related to preservice teacher education and program evaluation. Due to the complex and multidimensional nature of teaching (Darling-Hammond et al., 2012), scholars and policy holders have discussed the need to use multiple methods and measures to evaluate teacher effectiveness (Martinez et al., 2016). Classroom observation, surveys of teachers, parents or administrators, standardized tests, portfolios and value-added models are some of the most commonly used methods for measuring teacher effectiveness (Mayer, 1999; Martinez, 2012; Youngs \& Whittaker, 2015; Baker et al., 2010).

Some studies of teacher preparedness discuss the limitations of survey-based measures and suggest a need to compare self-perception data to other forms of data such as observational ratings (Ronfeldt et al., 2018). Such studies have been able to highlight important connections between specific features of teacher preparation programs and first-year teacher effectiveness (i.e. Ronfeldt et al., 2018). Thus, there is a need to continue investigating the potential connections between survey data and other forms of data in order to identify specific areas for improvement or accountability for teacher preparation programs.

Research related to program evaluation often highlights the importance of valid and reliable instruments or approaches. In order to maintain credible processes in a teacher preparation program, sound assessment practices must be in place. A key element of sound assessment practice is validity. According to Worrell et al., (2014) in order to determine the validity of the information collected for the program review, "one must decide the extent to which the measures being used in the evaluation relate to student teacher learning and student learning outcomes and the extent to which they do not" (p.41). Specifically, in the current study, content validity was established by multiple stakeholders who worked 
to align constructs represented in the measures with evidence to support each item. Another important element of sound assessment practice is reliability. According to Krippendorff (2011), reliability is the extent to which different methods, research results or people arrive at the same interpretations of facts ( $\mathrm{p}$. 94). The current study focused on inter-rater reliability, the extent to which members of the teacher preparation program agreed upon ratings for clinical evaluations.

\section{METHODOLOGY}

The current study employed a mixed methods phenomenological design that allowed us to collect multiple forms of data from a variety of sources. Surveys, interviews, and observations were used to investigate the extent to which completers were successful during their first three years after graduation from our Teacher Preparation Program.

\section{Participants}

Participants in the current study included first through third year completers of a Teacher Preparation Program from a small liberal arts college in Central Virginia. A purposeful sampling method was used in both qualitative and quantitative data collection (McMillan \& Schumacher, 2006). This approach was not a random sampling, but a sampling of participants who completed the EPP's program and are knowledgeable about teaching and learning. Our national accrediting agency, CAEP, recommended that we consistently use first through third year completers for each annual data collection cycle. On average, the EPP prepares 10-20 completers each academic year, with clinical experiences taking place in the spring semester. Therefore, each spring when completers are asked to voluntarily participate in data collection, an average of 35 completers are contacted.

\section{Design}

In this study, a phenomenological design was used to describe and analyze completer's impact on K12 student growth and learning. Since all participants share similar experiences in classroom instruction and assessment, a phenomenological study was appropriate to focus on one shared phenomenon to gain an in-depth understanding (McMillan \& Schumacher, 2006). According to Creswell (2007), a phenomenological design is used to develop a composite description of what participants have experienced and how they have experienced it.

Qualitative data collection involved asking teachers to participate in in-depth interviews (focus group meeting) in which the interview protocol focused on completers' effectiveness in measuring student learning and to what degree completers felt prepared to teach diverse learners and measure learning. Qualitative data were also collected through classroom observations of first-year teachers. Quantitative data collection involved asking employers and completers to participate in online surveys regarding teacher effectiveness and program preparedness. Quantitative data were also collected through Virginia Teacher Summative Performance Assessment (VDOE).

\section{Instruments and Procedure}

Completer data collection is conducted annually using a five-prong approach that includes employer surveys, completer surveys, focus groups, classroom observations, and voluntary submission of the Virginia Teacher Summative Performance Assessment.

The employer survey is conducted annually for all employers of first- through third-year completers (see Appendix A for survey items). The survey is voluntary, and results for AY 2017-2018 yielded a 53\% return rate (see Table 1). The completer survey is also conducted annually for all completers, firstthrough third year (see Appendix B for survey items). As a voluntary survey, the self-reported results from completers yielded a 46\% return rate for AY 2017-2018 (see Table 2). For both the employer and completer survey, all completers and their employers (administrators) were contacted by email with an invitation to participate in the survey using SurveyMonkey. Emails are sent during spring semester, and participants are given two weeks to complete, with one email reminder. 
As an additional data collection point, first- through third-year completers are contacted by email to voluntarily participate in a Completer Focus Group Meeting. Completers are assured of confidentiality in their responses and are asked to be honest and open regarding their experiences. Table 3 lists the interview protocol and subsequent responses from nine completers during a spring 2018 interview/focus group meeting. These self-reported completer responses provide useful and meaningful data to triangulate the effectiveness of their classroom teaching, instruction, and assessment.

In Table 4, data are listed from EPP faculty visits to first-year completers' classrooms. Visiting firstyear completers' classrooms is a priority for the EPP. Classroom visits average $60 \%$ of completers and provide useful data collection and analysis using direct observation. Using the EPP-created field and clinical evaluation assessment (see Appendix C), EPP faculty rated the completers on their effectiveness using the 10 InTASC Standards as expected for CAEP.

Table 5 lists voluntary data submission from first- through third-year completers on their summative evaluation by employers using the Virginia Teacher Summative Performance Assessment, developed by the state of Virginia, to evaluate all public classroom teachers of their professional growth and performance and impact on P-12 learning.

The EPP invested significant effort in establishing content validity to ensure that assessments measure what they are intended to measure. In establishing content validity, a representative sample of employers, both administrators and K-12 teacher mentors, participated in meetings to establish content validity of two EPP-created assessments: the employer survey and the field and clinical evaluation. During the same semester, a representative sample of completers (first- through third-year) participated in meetings to establish content validity of the completer survey and to participate in an open-forum focus group meeting. At all meetings, stakeholders were asked to explain what each assessment item meant to them and were asked to provide examples of evidence which would support the assessment item. Through discussions, data were collected and analyzed to revise the evaluation. If discrepancies existed, then evaluators had conversations about the meaning of the assessment item.

\section{RESULTS}

With the effective use of the five-prong approach, data results demonstrate that our teacher preparation program yield completers who effectively apply expected professional knowledge, skills, and dispositions to positively impact student learning, and program completers contribute to expected levels of student learning growth.

Employer survey results (Table 1) and completer survey results (Table 2) are consistent in identifying that completers meet InTASC standards in four categories (Learners and Learning, Content Knowledge, Instructional Practice, and Professional Responsibility) with combined rates above $75 \%$ as exemplary or proficient. Of notable interest, completers were inclined to self-rate their preparedness and effectiveness higher than employers.

\section{TABLE 1 \\ AY 2017-2018 EMPLOYER SURVEY RESULTS BY InTASC STANDARD, N=18 RESPONSE RATE $=53 \%(18 / 34)$}

\begin{tabular}{lcccccc}
\hline InTASC Standard & Exemplary & Proficient & Developing & Unacceptable & $\begin{array}{l}\text { Not } \\
\text { Observed }\end{array}$ & $\begin{array}{l}\text { \# of } \\
\text { Responses }\end{array}$ \\
\hline $\begin{array}{l}\text { Learners and } \\
\text { Learning }\end{array}$ & $44 \%$ & $38 \%$ & $19 \%$ & $1 \%$ & $0 \%$ & 106 \\
$\begin{array}{l}\text { Content Knowledge } \\
\text { Instructional }\end{array}$ & $28 \%$ & $50 \%$ & $22 \%$ & $0 \%$ & $0 \%$ & 54 \\
$\begin{array}{l}\text { Practice } \\
\text { Prof Responsibility }\end{array}$ & $40 \%$ & $55 \%$ & $21 \%$ & $0 \%$ & $1 \%$ & 124 \\
Mean \% & $34 \%$ & $44 \%$ & $18 \%$ & $6 \%$ & $0 \%$ & 33 \\
\hline
\end{tabular}


TABLE 2

AY 2017-2018 COMPLETER SURVEY RESULTS BY InTASC STANDARD, N=16

RESPONSE RATE $=47 \%(16 / 34)$

\begin{tabular}{lcccccc}
\hline $\begin{array}{l}\text { InTASC } \\
\text { Standard }\end{array}$ & Exemplary & Proficient & Developing & Unacceptable & $\begin{array}{l}\text { Not } \\
\text { Observed }\end{array}$ & $\begin{array}{l}\text { \# of } \\
\text { Responses }\end{array}$ \\
\hline $\begin{array}{l}\text { Learners and } \\
\text { Learning }\end{array}$ & $39 \%$ & $52 \%$ & $7 \%$ & $0 \%$ & $0 \%$ & 96 \\
$\begin{array}{l}\text { Content } \\
\text { Knowledge }\end{array}$ & $44 \%$ & $50 \%$ & $6 \%$ & $0 \%$ & $0 \%$ & 48 \\
$\begin{array}{l}\text { Instructional } \\
\begin{array}{l}\text { Practice } \\
\text { Prof }\end{array}\end{array}$ & $42 \%$ & $50 \%$ & $5 \%$ & $0 \%$ & $2 \%$ & 105 \\
$\begin{array}{l}\text { Responsibility } \\
\text { Mean \% }\end{array}$ & $75 \%$ & $18 \%$ & $7 \%$ & $0 \%$ & $0 \%$ & 28 \\
\hline
\end{tabular}

Qualitative responses (Table 3) collected during the completer focus group provided meaningful data about student learning and measuring student progress. Analyzing qualitative responses with completer survey responses yielded consistent feedback concerning the completers' effectiveness and positive impact on K-12 student learning.

TABLE 3

AY 2017 -2018 COMPLETER FOCUS GROUP INTERVIEW PROTOCOL AND RESPONSES, $\mathbf{N}=9$

\begin{tabular}{ll}
\hline Focus Group Question & Summary of Completer Responses \\
\hline 1. How do you know students are learning? & $\begin{array}{l}\text { Completers indicated that they know students are } \\
\text { learning when students ask questions; answer }\end{array}$ \\
questions; discuss on topic; can relate topic to \\
themselves; are able to teach someone else, and \\
when students can apply new learning consistently \\
to future lessons. \\
Completers indicated that they effectively measure \\
2tudent learning through the students learning \\
progressions. Examples included through prescribed \\
reading programs (such as Fountas and Pinnell); \\
analyses of benchmark testing by student by \\
question; written and verbal responses in class; \\
music festivals; IEP goal progress data; choice and \\
menu board assessments; journaling; lab \\
experiments; literature circles, and via Socratic \\
Seminars
\end{tabular}


Focus Group Question $\quad$ Summary of Completer Responses

3. What strategies have you found beneficial for Completers indicated that the most beneficial measuring student progress?

instructional strategies include anchor charts; guided notes and discussion; jigsaw; station work; small groups; library visits; cross-curricular lessons;' skill-based reading in small groups, and choice boards. Completers indicated that the most beneficial assessment strategies include collaborative work; tests; essays; discussion; literature circles with assigned roles, and technology applications on tablets. Completers indicated that the most beneficial management strategies included small groups; teaching stations; providing choice; developing respect; setting clear expectations and building relationships.

4. What strategies have you changed?

Completers indicated that the change in instructional strategy that had the most positive impact was changing how to use worksheets in the classroom. Completers indicated that integrating technology with Google classroom turned worksheets into interactive and engaged activities for students.

5. What factors do you consider as academic achievement?

Completers defined academic achievement as growth in students' academics; when students express their successes, and progress/growth on assessments over time.

6. What factors impede your students' learning? Completers' views on factors that impede students' learning were many. They include home life; negative peer relations; refusal to complete work; laziness; relationships with teachers; anxiety; bullying; low intrinsic motivation; self-esteem; fixed mindsets, hormones, and lack of discipline from school administration.

7. How is Performance Standard \#7 goal tied to Completers all agreed that administrators and grade your students' learning and achievement? level assistance help develop focused goals for each teacher based on previous student data. Administrators want teachers to design appropriate grade-level goals, and near the end of the academic year, teachers collect evidence and write a summary which speaks to measuring how well the goal was met. Completers all agreed that their administrators expect to see student progress

General comments:

Feedback on the degree to which the EPP prepared them for this work: During concluding remarks, completers spoke again to the "joyful learning" that was characteristic of the EPP. They focused on teacher self-reflection, professional learning communities, collaboration, and relationship-building with students as strengths of the program. These, they said, were the key skills taught during their time as candidates and that prepared them to be successful educators. 
Data collected in Tables 4 and 5 are consistent with respect to measuring completer effectiveness by evaluation from the EPP and the completer's employer. Mean scores from both instruments indicate that scores are reliable and similar in measuring completer effectiveness and impact on K-12 student learning.

TABLE 4

FIELD AND CLINICAL EVALUATION (EPP CREATED)

Completer Clinical Evaluation Ratings, AY 2017 - 2018, N=6

\begin{tabular}{|c|c|c|c|c|c|c|c|c|}
\hline Scoring Range: $1-4$ & Completer & $\# 1$ & $\# 2$ & $\# 3$ & $\# 4$ & $\# 5$ & $\# 6$ & $\begin{array}{c}\text { Average } \\
\text { Rating }\end{array}$ \\
\hline Learning and Learners & & 3.0 & 3.0 & 3.0 & 3.0 & 3.0 & 3.0 & 3.0 \\
\hline Content Knowledge & & 3.0 & 2.0 & 3.0 & 3.0 & 4.0 & 3.0 & 3.0 \\
\hline Instructional Practice & & 3.0 & 3.0 & 3.0 & 3.0 & 3.0 & 2.0 & 2.8 \\
\hline Professional Responsibility & & 3.0 & 3.0 & 2.0 & 3.0 & 3.0 & 2.0 & 2.7 \\
\hline Average per Completer & & 3.0 & 2.8 & 2.8 & 3.0 & 3.25 & 2.5 & 2.9 \\
\hline
\end{tabular}

Ratings: $4.0=$ Exemplary, $3.0=$ Proficient, $2.0=$ Developing/Needs Improvement, $1.0=$ Unacceptable

TABLE 5

SY 2017-2018 VIRGINIA TEACHER SUMMATIVE PERFORMANCE ASSESSMENT (FROM VDOE) EMPLOYERS RATINGS ON COMPLETERS' IMPACT TO STUDENT LEARNING, $\mathbf{N}=8$

\begin{tabular}{|c|c|c|c|c|c|c|c|c|c|}
\hline Standards & 1 & $2 *$ & 3 & 4 & $5 *$ & 6 & 7 & 8 & Means \\
\hline $\begin{array}{l}\text { Student } \\
\text { Learning }\end{array}$ & 3 & $\mathrm{NA}$ & 3 & 3 & NA & 2 & 3 & 3 & 2.8 \\
\hline $\begin{array}{l}\text { Instructional } \\
\text { Knowledge }\end{array}$ & 3 & NA & 3 & 3 & NA & 3 & 4 & 3 & 3.2 \\
\hline $\begin{array}{l}\text { Instructional } \\
\text { Delivery }\end{array}$ & 4 & NA & 3 & 3 & NA & 2 & 3 & 3 & 3.0 \\
\hline $\begin{array}{l}\text { Assessing } \\
\text { Student } \\
\text { Learning }\end{array}$ & 3 & NA & 3 & 3 & NA & 2 & 3 & 3 & 2.8 \\
\hline $\begin{array}{l}\text { Learning } \\
\text { Environment }\end{array}$ & 4 & NA & 3 & 4 & NA & 2 & 4 & 4 & 3.5 \\
\hline Professionalism & 3 & NA & 3 & 3 & NA & 3 & 3 & 4 & 3.2 \\
\hline $\begin{array}{l}\text { Student } \\
\text { Academic } \\
\text { Progress }\end{array}$ & 3 & 3 & 3 & 3 & 3 & 3 & 4 & 3 & 3.1 \\
\hline Means & 3.3 & -* & 3.0 & 3.1 & -* & 2.4 & 3.4 & 3.3 & 3.1 \\
\hline
\end{tabular}

* Completer did not submit employer ratings on all standards.

Given these results, data triangulate to form a comprehensive picture that both employers and completers find that completers are positively impacting K-12 student growth and learning in the classrooms.

\section{SIGNIFICANCE AND CONTRIBUTIONS}

The findings presented here demonstrate not only the success our completers experience following graduation from our teacher preparation program, but they also provide important data to support the effectiveness of our five-prong approach. While more data collection is needed to demonstrate 
consistency, the findings from this study are useful as a baseline for consideration when building a multipronged approach to assessing completer impact.

Consistent with the literature regarding the importance of using multiple measures to evaluate teacher effectiveness (Martinez e al., 2016), the current research provides a model for using both quantitative and qualitive methods to thoroughly analyze a teacher education program. The findings also build upon the research that discusses the importance of connecting survey data to classroom observations (i.e. Ronfeldt et al., 2018) and demonstrates that, in this context, the observational data supported the survey findings.

Meeting national accreditation standards underscored the need to develop meaningful, valid, and reliable measurement instruments. Consistent with the literature, it is important to focus on instrument validity and reliability to produce sound assessment practices (Krippendorff, 2011; Worrell et al., 2014). The outcomes of our instrument validity and reliability meetings assisted in producing sound assessments yielding valid and reliable data for continuous improvement purposes. As we continue to disaggregate data even further by endorsement program, we anticipate that we will find greater areas of strengths and weaknesses in teacher preparation as it relates to transitioning to the K-12 classroom. For example, we anticipate that secondary education candidates will have greater ratings in content knowledge since they major in content-related fields.

\section{REFERENCES}

Baker, E.L., Barton, P.E., Darling-Hammond, L., Haertel, E., Ladd, H.F., Linn, R.L., . . Shepard, L.A. (2010). Problems with the use of student test scores to evaluate teachers. Washington, DC: Economic Policy Institute.

Creswell, J.W. (2007). Qualitative inquiry and research design: Choosing among five traditions (2nd ed.). Thousand Oaks, CA: Sage Publications.

Krippendorff, K. (2009). Testing the Reliability of Central Analysis Data: What is Involved and Why. In The Content Analysis Reader, edited by K.H. Krippendorff \& M.A. Bock (pp. 350-357). Thousand Oaks, CA: Sage Publication.

Martínez, J.F. (2012). Consequences of omitting the classroom in multilevel models of schooling: An illustration using opportunity to learn and reading achievement. School Effectiveness and School Improvement, 23, 305-326.

Martínez, J.F., Schweig, J., \& Goldschmidt, P. (2016). Approaches for combining multiple measures of teacher performance: Reliability, validity, and implications for evaluation policy. Educational Evaluation and Policy Analysis, 38(4), 738-756.

Mayer, D. (1999). Measuring instructional practice: Can policy makers trust survey data? Educational Evaluation and Policy Analysis, 21(1), 29-45.

McMillan, J.H., \& Schumacher, S. (2006). Research in education: A conceptual introduction. New York: Longman.

National Academy of Education. (2005). A good teacher in every classroom: Preparing the highly qualified teachers our children deserve. Committee on Teacher Education, edited by L. DarlingHammond \& J. Baratz-Snowden (Eds.). San Francisco, CA: Jossey-Bass.

National Research Council. (1982). Ability testing: Uses, consequences, and controversies, parts I and II. Committee on Ability Testing, edited by A.K. Wigdor \& W.R. Garner (Eds.). Washington, DC: National Academy Press.

Ronfeldt, M., Matsko, K.K., Greene Nolan, H., \& Reininger, M. (2018). Who Knows if Our Teachers Are Prepared? Three Different Perspectives on Graduates' Instructional Readiness and the Features of Preservice Preparation That Predict Them. CEPA Working Paper No. 18-01. Stanford Center for Education Policy Analysis.

Shulman, L.S. (1986). Those who understand: Knowledge growth in teaching. Educational Researcher, $15(2), 4-14$

114 Journal of Higher Education Theory and Practice Vol. 20(8) 2020 
Worrell, F.C., Brabeck, M.M., Dwyer, C.A., Geisinger, K.F., Marx, R.W., Noell, G.H., \& Pianta, R.C. (2014). Assessing and evaluating teacher education programs. Washington, DC: American Psychological Association.

Youngs, P., \& Whittaker, A. (2015). The role of EdTPA in assessing content specific instructional practices. In P. Youngs \& J. Grissom (Eds.), Improving teacher evaluation systems (pp. 89-101). New York, NY: Teachers College Press. 


\section{APPENDIX A}

\section{Employer Survey}

For each of the following items, participants are asked to rate the degree to which the teacher demonstrates that the Teacher Preparation Program prepared them as Exemplary, Proficient, Developing/Needs Improvement, or Unacceptable.

1. Demonstrate your understanding of how learners grow and develop, including recognition of intellectual, emotional, and physical differences, by designing and implementing developmentally appropriate learning experiences?

2. Demonstrate an understanding of diverse cultures and communities by creating inclusive learning environments?

3. Work with colleagues to create environments that support individual and collaborative learning and encourage positive social interaction, active engagement in learning, and self-motivation?

4. Work with students to create environments that support individual and collaborative learning and encourage positive social interaction, active engagement in learning, and self-motivation?

5. Work with families of students to create environments that support individual and collaborative learning, and that encourage positive social interaction, active engagement in learning, and selfmotivation?

6. Effectively manage the classroom to create an environment that supports individual and collaborative learning and encourages positive social interaction, active engagement in learning, and self-motivation?

7. Effectively teach the content in his/her licensure area?

8. Engage learners in critical thinking, creativity, and collaborative problem-solving related to local and global topics?

9. Use a variety of instructional strategies that encourage learners to apply knowledge in meaningful ways?

10. Plan lessons with clear learning objectives/goals in mind by drawing upon knowledge of content areas, curriculum, and pedagogy?

11. Integrate a variety of media and educational technology into your instruction?

12. Design formative assessments?

13. Use formative data to drive instruction?

14. Design summative assessments?

15. Provide evidence of acceptable, measurable, and appropriate student progress?

16. Engage in continuous learning and professional development, and use evidence to continually evaluate your teaching practice?

17. Seek appropriate leadership roles and opportunities?

Participants were also provided opportunities to add additional comments throughout the survey. 


\section{APPENDIX B}

\section{Completer Survey}

For each of the following items, participants are asked to rate the degree to which the Teacher Preparation Program prepared them as Exemplary, Proficient, Developing/Needs Improvement, or Unacceptable.

1. Demonstrate your understanding of how learners grow and develop, including recognition of intellectual, emotional, and physical differences, by designing and implementing developmentally appropriate learning experiences?

2. Demonstrate an understanding of diverse cultures and communities by creating inclusive learning environments?

3. Work with colleagues to create environments that support individual and collaborative learning and encourage positive social interaction, active engagement in learning, and selfmotivation?

4. Work with students to create environments that support individual and collaborative learning and encourage positive social interaction, active engagement in learning, and self-motivation?

5. Work with families of students to create environments that support individual and collaborative learning, and that encourage positive social interaction, active engagement in learning, and self-motivation?

6. Effectively manage the classroom to create an environment that supports individual and collaborative learning and encourages positive social interaction, active engagement in learning, and self-motivation?

7. Effectively teach the content in your licensure area?

8. Engage learners in critical thinking, creativity, and collaborative problem-solving related to local and global topics?

9. Use a variety of instructional strategies that encourage learners to apply knowledge in meaningful ways?

10. Plan lessons with clear learning objectives/goals in mind by drawing upon knowledge of content areas, curriculum, and pedagogy?

11. Integrate a variety of media and educational technology into your instruction?

12. Design formative assessments?

13. Use formative data to drive instruction?

14. Design summative assessments?

15. Provide evidence of acceptable, measurable, and appropriate student progress?

16. Engage in continuous learning and professional development, and use evidence to continually evaluate your teaching practice?

17. Seek appropriate leadership roles and opportunities?

Participants were also provided opportunities to add additional comments throughout the survey. 


\section{APPENDIX C}

\section{Field and Clinical Evaluation}

For each of the following items, completers are rated as one of the following: Exemplary, Proficient, Developing, Unacceptable or Not Observed.

1. Has regular attendance and is punctual and reliable.

2. Demonstrates a spirit of flexibility, cooperation, and collaboration.

3. Has professional appearance and attire.

4. Maintains confidentiality.

5. Develops relationships and interacts positively with host teacher and school personnel.

6. Demonstrates appropriate confidence and poise.

7. Represents self, Randolph-Macon College, and the profession of teaching as a positive role model.

8. Seeks opportunities to participate in the school community beyond the classroom.

9. PROFESSIONAL RESPONSIBILITY: Please provide specific example(s) as evidence of the teacher candidate's performance in this area. If the rating was developing or unacceptable, please offer recommendations for improvement. [The evaluator might consider candidate's presentation of self and the relationships s/he has developed with faculty, families, and students at the school. The evaluator might also consider candidate's participation in grade-level, schoollevel or community events. The evaluator might cite specific examples of professionalism demonstrated by the candidate.]

10. Applies understandings of each learner's developmental differences (intellectual, social, personal) in the context of teaching.

11. Applies understandings of each learner's unique culture and experience in the context of teaching.

12. Builds positive relationships with and among students, fostering an environment that values and encourages respect for diversity.

13. Maintains a physically and emotionally safe learning environment for all students.

14. Demonstrates effective classroom management skills.

15. THE LEARNER \& LEARNING: Please provide specific example(s) as evidence of the teacher candidate's performance in this area. If the rating was developing or unacceptable, please offer recommendations for improvement. [The evaluator may consider candidate's lesson planning and preparation that takes into consideration diverse learner's needs and backgrounds. The evaluator might also cite examples where the candidate worked with individual or groups of students to meet specific needs or made an effort to build relationships with students and families across cultural lines of difference. The evaluator may also consider efforts the candidate made to develop a positive, inclusive community and manage the flow of classroom activities.]

16. Demonstrates understanding of academic content for instruction.

17. Makes content accessible and relevant to students (i.e., anticipates misconceptions, uses powerful analogies or examples, breaks down central concepts or processes).

18. Creates learning opportunities for students to think critically, creatively, and collaboratively.

19. CONTENT KNOWLEDGE: Please provide specific example(s) as evidence of the teacher candidate's performance in this area. If the rating was developing or unacceptable, please offer recommendations for improvement. [The evaluator may consider insights the candidate has about connecting content to student experience, materials or methods used to make content relevant and accessible to students, activities included to challenge student thinking about a topic.]

20. Selects appropriate materials/resources that align with articulated learning objectives.

21. Plans instruction that supports every student in meeting appropriately challenging learning goals. 
22. Creates and selects multiple assessments that adequately measure learning of the stated learning objectives.

23. Uses data sources to assess the effectiveness of instruction and make instructional decisions.

24. Utilizes various instructional strategies to develop deep understanding of content.

25. INSTRUCTIONAL PRACTICE: Please provide specific example(s) as evidence of the teacher candidate's performance in this area. If the rating was developing or unacceptable, please offer recommendations for improvement. [The evaluator may cite specific methods or materials used to deepen student learning, including manipulative, simulations, art, role play, online or computer programs, etc. The evaluator might also cite specific examples of creative instruction that challenged students. Evaluator may cite specific assessments developed by the candidate and how the candidate made sense of student performance on that assessment.] 